\title{
Release of doxorubicin from its liposomal coating via high intensity ultrasound
}

\author{
AGATA MIKOLAJCZYK $^{1 *}$, VERIA KHOSRAWIPOUR ${ }^{2 *}$, JOANNA KULAS $^{1}$, KLAUDIA KOCIELEK $^{1}$, \\ PAWEL MIGDAL $^{3}$, MOHAMED ARAFKAS $^{4}$ and TANJA KHOSRAWIPOUR ${ }^{5,6}$
}

\begin{abstract}
${ }^{1}$ Department of Biochemistry and Molecular Biology, Faculty of Veterinary Medicine, Wroclaw University of Environmental and Life Sciences, 50-373 Wroclaw, Poland; ${ }^{2}$ Department of Orthopedic and Trauma Surgery, Ortho-Klinik Dortmund, Dortmund D-44263, Germany; ${ }^{3}$ Department of Environment, Hygiene and Animal Welfare, Wroclaw University of Environmental and Life Sciences, 50-373 Wroclaw, Poland; ${ }^{4}$ Department of Plastic Surgery, Ortho-Klinik Dortmund, Dortmund D-44263, Germany; ${ }^{5}$ Department of Surgery, Division of Colorectal Surgery, University of California, Irvine, Orange, CA 92868, USA; ${ }^{6}$ Department of Surgery (A), University-Hospital Düsseldorf, Düsseldorf D-40225, Germany
\end{abstract}

Received April 9, 2019; Accepted June 21, 2019

DOI: $10.3892 / \mathrm{mco} .2019 .1917$

\begin{abstract}
The present ex vivo study was performed to analyze the impact of high intensity ultrasound (HIUS) on penetration depth and particle stability of liposomal doxorubicin (LD) on the peritoneal surface. Fresh post mortem swine peritoneum was cut into proportional sections and subjected to a previously established ex vivo model of pressurized intraperitoneal aerosol chemotherapy (PIPAC). Samples were treated with $50 \mathrm{ml}$ $\mathrm{NaCl}(0.9 \%)$ containing $3 \mathrm{mg}$ LD via PIPAC or lavage. In both groups, half of the samples received additional HIUS treatment. Samples treated via PIPAC were covered with a 30-mm-thick abdominal muscle wall tissue, fatty tissue and skin, followed by transcutaneous HIUS. Samples administered with LD via lavage received close-range contact HIUS. Doxorubicin tissue penetration was measured using fluorescence microscopy on frozen sections. Liposomal integrity on peritoneal surfaces was measured via electron microscopy (EM). Mean penetration rates of doxorubicin were significantly higher with HIUS in combination with PIPAC or lavage compared with PIPAC alone $(\mathrm{P}<0.001)$ or lavage alone $(\mathrm{P}<0.00001)$. LD was not detected on the peritoneal surface via EM analysis in either group following
\end{abstract}

Correspondence to: Dr Tanja Khosrawipour, Department of Surgery, Division of Colorectal Surgery, University of California, 333 City Boulevard West, Irvine, Orange, CA 92868, USA

E-mail: tkhosrawipour@gmail.com

${ }^{*}$ Contributed equally

Abbreviations: EM, electron microscopy; HIUS, high intensity ultrasound; IPC, intraperitoneal chemotherapy; LD, liposomal doxorubicin; MC, microcatheter; PIPAC, pressurized intraperitoneal aerosol chemotherapy; PM, peritoneal metastasis

Key words: ultrasound, drug penetration, PIPAC, PM, LD
HIUS. The present data suggested that HIUS may be a feasible application that can facilitate the release of doxorubicin from its liposomal envelope. HIUS was effective in both close-range, in contact with the samples, and through the abdominal wall. The present approach may be used in the future for both endoscopic and open lavage of the peritoneal cavity with LD in intraperitoneal chemotherapeutic applications such as hyperthermic intraperitoneal chemotherapy or PIPAC.

\section{Introduction}

Pressurized intraperitoneal aerosol chemotherapy (PIPAC) has been suggested as an innovative approach for the application of intraperitoneal chemotherapy (IPC) (1). The drug-containing solution is delivered into the abdominal cavity as microparticles using an aerosol-producing device $(2,3)$. Penetration depth of PIPAC has been observed to be superior to liquid applications and research on this field is ongoing (4-6). New combinations of drugs and carrier molecules are currently being tested for intraperitoneal delivery and especially for PIPAC applications (7).

Previous studies have been conducted to evaluate the effects of new substances and other strategies to apply PIPAC with the aim to enhance drug availability (8-10). Previous studies focusing on the use of coated particles, such as liposomal doxorubicin (LD) for IPC, have shown promising results $(11,12)$. However, previous studies on LD have indicated that the pharmacology of liposomal particles is quite complex, since, in contrast to regular doxorubicin, LD particles do not release their drug content easily at the target site $(7,13)$. A recent study has investigated the effect of LD on the peritoneal surface, describing that particles on the surface remain stable and a small amount of doxorubicin is delivered to the local peritoneal tissue (7). Similar observations have been documented in the application of liquid IPC where LD is at least partially detectable in the plasma (12).

However, particles applied locally or intravenously accumulate in certain organs, including the kidneys and the heart, 
causing local toxicity $(14,15)$. These side effects limit the use of LD for intraperitoneal applications. In some applications, high intensity ultrasound (HIUS) has demonstrated to facilitate the release of doxorubicin from LD particles (16). Notably, a clinical trial indicated promising antitumoral effects (17).

However, it is unclear whether the content of these liposomal-coated particles can be released on the peritoneal surface using HIUS. Moreover, if the release of doxorubicin is increased, it remains unclear whether this is relevant for the drug absorption rate in the peritoneum. Therefore, HIUS may facilitate the use of these particles for IPC treatments. The aim of the present study was to evaluate the effect of HIUS combined with LD administration on the peritoneal surface compared with $\mathrm{LD}$ administration without HIUS using an established ex vivo model.

\section{Materials and methods}

Ex vivo PIPAC model. Since the experiments were performed in an ex vivo model using commercially available tissue samples (local pork supplier, Zerniki Wielkie), no approval from the Local Board on Animal Care was required. Fresh post mortem swine peritoneum samples were cut into smaller pieces of 40x40x5 mm.

PIPAC procedure. A commercially available hermetically sealable plastic box, representing the abdominal cavity, was used. The ex vivo PIPAC model was established as previously described $(18,19)$. Fresh tissue samples from swine peritoneum (size, $40 \times 40 \times 5 \mathrm{~mm}$ ) were placed at the bottom of the box. A trocar of $5 \mathrm{~mm}$ in diameter (Kii Balloon Blunt Tip System; Applied Medical Resources Corporation) was placed in the center of the lid. The nozzle of a microcatheter (MC; Olympus PW-205V; Olympus Corporation) was introduced into the trocar. The ex vivo model was kept at a constant room temperature of $27^{\circ} \mathrm{C}$ during the entire procedure. The entire procedure lasted $30 \mathrm{~min}$, including the injection phase and the exposure phase after aerosolization.

The distance between the nozzle of the MC and the bottom of the plastic box was $10 \mathrm{~cm}$. The plastic box was tightly sealed and a constant $\mathrm{CO}_{2}$ capnoperitoneum pressure of $12 \mathrm{mmHg}$ (Olympus UHI-3; Olympus Corporation) was maintained during the entire PIPAC procedure. In total, $3 \mathrm{mg}$ LD (Caelyx ${ }^{\circledR}$; Janssen-Cilag Ltd.; Johnson and Johnson; cat. no. BHZ0V00) were dissolved in $50 \mathrm{ml} \mathrm{NaCl}(0.9 \%)$ at $27^{\circ} \mathrm{C}$ and administered via MC.

Ultrasound of treated PIPAC samples. All tissue samples were removed from the ex vivo model and covered with a 30-mm-thick tissue section of the abdominal wall containing parietal peritoneum, muscle, adipose tissue and abdominal skin. The samples for transcutaneous HIUS consisted of two attached peritoneal tissue samples forming an intraperitoneal cavity with two opposing peritoneal layers. Half of the samples were treated with HIUS. During HIUS, the tip of the probe was in direct contact with the abdominal wall (Fig. 1A). Sonication was applied for $30 \mathrm{sec}$ at a frequency of $20 \mathrm{kHz}$, an output power of $70 \mathrm{~W}$ and an amplitude of $50 \%$.

Ultrasound of samples treated by lavage. Other peritoneal tissue samples were placed in a Petri dish and covered by a solution containing $3 \mathrm{mg}$ of $\mathrm{LD}$ dissolved in $50 \mathrm{ml} \mathrm{NaCl}$
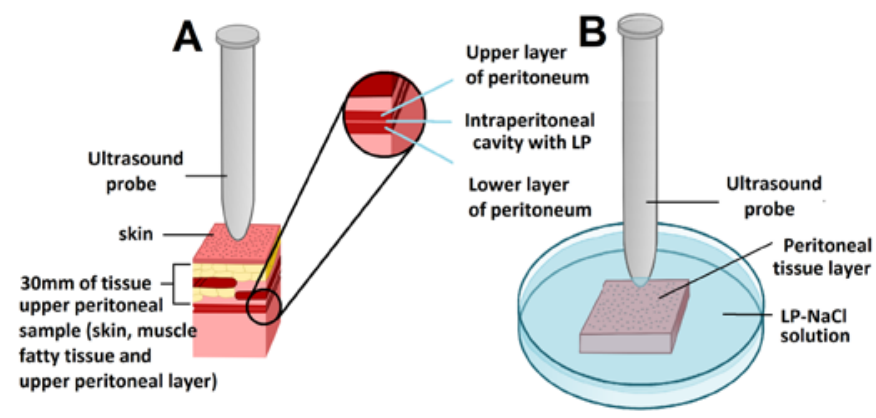

Figure 1. Ex vivo experiment on fresh swine peritoneum with transcutaneous and directly-applied HIUS after PIPAC. (A) Transcutaneous HIUS via ultrasound probe after LD treatment via PIPAC procedure. Sample consisted of two attached peritoneal tissue samples creating an intraperitoneal cavity with two opposing peritoneal layers. (B) Directly-applied HIUS on peritoneal tissue layer after lavage in a Petri dish filled with a $\mathrm{LD}-\mathrm{NaCl}$ solution. HIUS, high intensity ultrasound; PIPAC, pressurized intraperitoneal aerosol chemotherapy; LD, liposomal doxorubicin.

(0.9\%). A HIUS probe was placed in the Petri dish (Fig. 1). The tip of the probe was positioned at a distance of $3 \mathrm{~mm}$ from the surface of the peritoneum (Fig. 1B). Sonication was applied for $30 \mathrm{sec}$ at a frequency of $20 \mathrm{kHz}$, an output power of $70 \mathrm{~W}$ and an amplitude of $50 \%$.

Microscopic analysis. After treatments, all tissue samples were rinsed with sterile $\mathrm{NaCl}(0.9 \%)$ solution in order to eliminate superficial drug particles and immediately frozen in liquid nitrogen. Cryosections at $-25^{\circ} \mathrm{C}$ (thickness, $10 \mu \mathrm{m}$ ) were prepared from different areas of each specimen. Sections were mounted with VectaShield mounting media containing $1.5 \mu \mathrm{g} / \mathrm{ml}$ DAPI to stain nuclei at room temperature $\left(27^{\circ} \mathrm{C}\right)$. Penetration depth of doxorubicin was monitored using a Nikon Eclipse 80i fluorescence microscope (Nikon Corporation; magnification, x10) to detect intrinsic doxorubicin fluorescense. The distance between the luminal surface and the innermost positive staining for doxorubicin accumulation was measured and reported in $\mu \mathrm{m}$ (Figs. 2 and 3).

$L D$ detection via electron microscopy $(E M)$. The surface of the peritoneal tissue samples treated with LD was analyzed and visualized via cryogenic scanning EM (cryo-SEM) (Fig. 4). Tissue samples were fixed overnight at $-5^{\circ} \mathrm{C}$ in $2.5 \%$ glutaraldehyde solution in PBS (pH 7.2). After fixation, samples were washed in PBS, rinsed in ultrapure deionized water, which was filtered through syringe filters (pore diameter, $0.1 \mu \mathrm{m}$ ), mounted on a cryoshuttle using a mixture containing optimal cutting temperature compound and colloid graphite, and immersed in liquid nitrogen. The frozen specimen was then quickly transferred to a cryo-preparation chamber (Cryo Quorum PP3010T; Quorum Technologies Ltd.), sputtered with a conductive layer of platinum at $-140^{\circ} \mathrm{C}$, and transferred to the microscope chamber maintaining the same temperature of $-140^{\circ} \mathrm{C}$ (Auriga 60; Zeiss AG). Samples were observed at $2 \mathrm{kV}$ of acceleration voltage using In-Lens and Type II secondary electron detectors.

Statistical analysis. Experiments were independently performed three times. In total, 12 Cryosections per tissue sample were subject to doxorubicin penetration measurements. Data are presented as the mean $\pm \mathrm{SD}$. The statistical analyses 
A

Transcutaneous high-intensity ultrasound

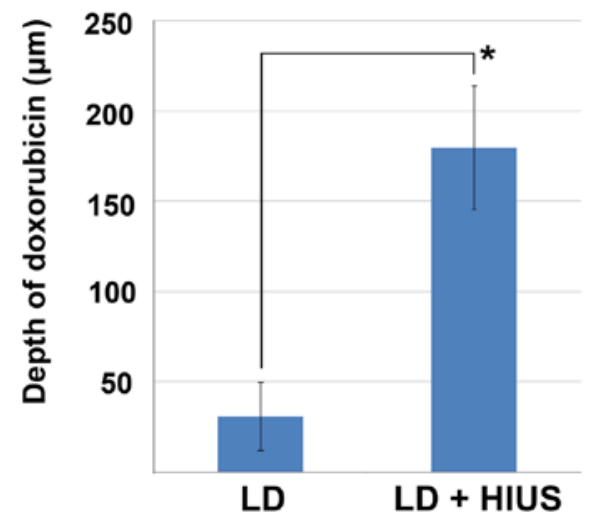

B

\section{Close range high-intensity ultrasound}

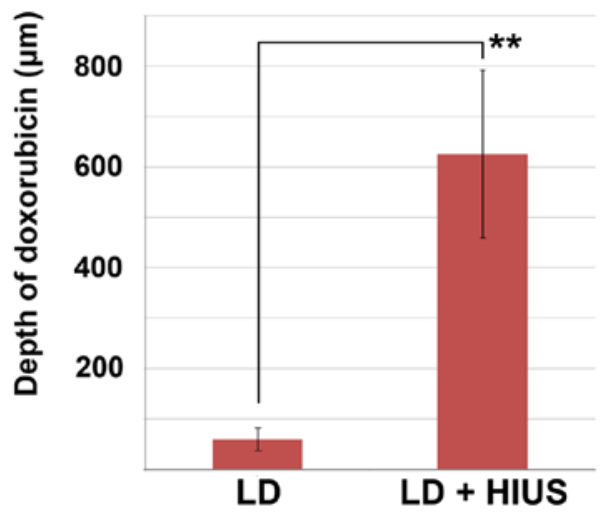

Figure 2. Tissue penetration depth of LD before and after HIUS. (A) Doxorubicin penetration depth after PIPAC with and without treatment with transcutaneous HIUS. (B) Doxorubicin depth after lavage with and without treatment with close-range HIUS. ${ }^{*} \mathrm{P}<0.001,{ }^{* *} \mathrm{P}<0.00001$. LD, liposomal doxorubicin; HIUS, high intensity ultrasound; PIPAC, pressurized intraperitoneal aerosol chemotherapy.

A

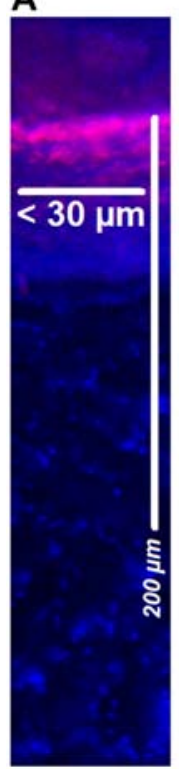

B

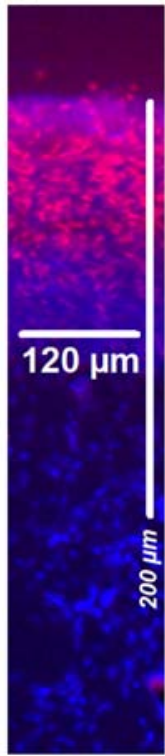

Figure 3. Microscopic analysis of doxorubicin penetration depth in fresh swine peritoneal tissue samples. (A) LD penetration without HIUS. (B) Microscopic analyses of LD penetration following HIUS. Nuclei, in blue, were stained with DAPI. HIUS, high intensity ultrasound; LD, liposomal doxorubicin.

were performed using Sigma Plot (version 12; Systat Software Inc.). The Kruskal-Wallis test by ranks was used for analyzing independent groups. $\mathrm{P}<0.01$ was considered to indicate a statistically significant difference.

\section{Results}

Ex vivo experiment. Mean penetration of doxorubicin following PIPAC-mediated LD treatment was $31 \pm 19 \mu \mathrm{m}$. In some of these samples, doxorubicin was undetectable by fluorescence microscopy. After PIPAC and transcutaneous HIUS, the mean penetration rates were significantly increased, and the mean was $180 \pm 35 \mu \mathrm{m}(\mathrm{P}<0.001$; Fig. $2 \mathrm{~A})$. No structural damage was detected in the peritoneal tissue after PIPAC and HIUS. Mean penetration of doxorubicin after lavage with LD
A

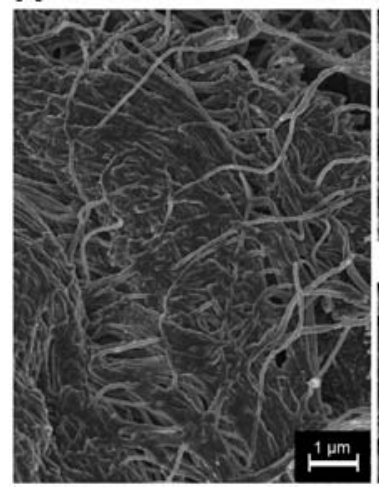

B

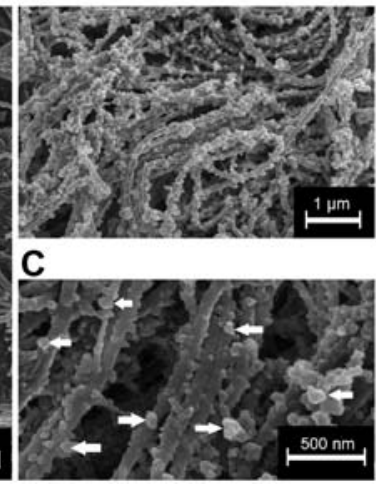

Figure 4. Cryogenic scanning electron microscopy of peritoneal surface. (A) Peritoneal surface treated with transcutaneous HIUS. No liposomal nanoparticles are detectable. (B) Peritoneal surface of samples treated with liposomal doxorubicin and without HIUS. Peritoneal surface is covered by liposomal nanoparticle. (C) Higher magnification of the peritoneal surface following liposomal doxorubicin treatment without HIUS. Arrows indicate single liposomes. HIUS, high intensity ultrasound.

was $60 \pm 22 \mu \mathrm{m}$. After close-range HIUS, the penetration depth of doxorubicin was $625 \pm 166 \mu \mathrm{m}$. The levels of LD measured following close-range HIUS were significantly higher ( $\mathrm{P}<0.00001$; Fig. 2B). Samples treated only via lavage did not show any structural damage; however, lavage samples treated with HIUS presented signs of structural alterations. Discrete structural damage was observed in few samples in the form of partial disruptions within the upper peritoneal layer. These defects were observed also in the subperitoneal tissue (data not shown). Doxorubicin was detected via fluorescence microscopy on the peritoneal surface at different depths (Fig. 3).

EM of peritoneal tissue. LD was detected on the peritoneal surface of samples that were not treated with HIUS via cryo-SEM (magnification, x20,000; Fig. 4B). Most LD particles had a spherical form and were $<200 \mathrm{~nm}$ in diameter. LD particles were detected throughout the entire surface. No LD particles were detected on the surface of the samples treated with transcutaneous HIUS (Fig. 4A). 


\section{Discussion}

Despite progress in chemotherapeutic regimens and new drug compositions, poor response to systemic and local treatment is still observed in a considerable part of patients suffering from peritoneal metastasis (PM), due to the occurrence of molecular mechanisms causing drug resistance and limited drug availability within the tumor tissue $(20,21)$. New forms of applications such as PIPAC, pressurized intravesical aerosol therapy and others alongside new drugs for intraperitoneal administration have been introduced and tested $(7,22,23)$.

PIPAC has been demonstrated to be a possible novel application method to administer new complex particles without altering their structural integrity (24). Furthermore, in contrast with liquid drugs, high local drug concentrations can be achieved with smaller quantities of applied volume (5).

Coated particles, including LD, have been described as good carriers for chemotherapeutics (25). In particular, LD has attracted high interest because of its ability to carry high concentrations of doxorubicin in proximity to malignant cells and release it on contact or in proximity to the cell wall (26). However, the main problem of LD is that the entire content of doxorubicin is not released in proximity to the target sites $(7,27)$.

In a previous study, HIUS was reported to be able to destroy the liposomal wall of $\mathrm{LD}$, facilitating the release of doxorubicin (16). As assessed by the present study via EM, the liposomal coating of LD appeared damaged in tissues treated with HIUS compared with tissues that were not subjected to HIUS. In line with previous studies, the present results suggested that HIUS can mediate the release of doxorubicin from its liposomal coating on the peritoneal surface, thus significantly increasing drug penetration. This effect induces a 5-10 time increase in tissue penetration at the target destination. Further in vivo and clinical studies are required to evaluate the relevance and efficacy of PIPAC with LD and HIUS.

Recent clinical trials on PIPAC have shown promising results with good overall drug tolerance for the application of chemotherapy in standard dosages $(28,29)$. Future clinical dose-escalation trials may identify the limits of standard liquid chemotherapy. In addition, thanks to these recent developments, liposomal particles such as LD may play a significant role in the future treatment of PM. These particles have been better tolerated compared to conventional liquid chemotherapy $(30,31)$. Drug release can increase with time and be enhanced by ultrasound, hyperthermia or other methods, as previously described $(32,33)$. Since the interaction of complex particles with peritoneal tissue has not yet been fully investigated, further studies are required to analyze benefits and disadvantages of LD application with HIUS.

The present results indicated that doxorubicin release may be limited in LD applications. This effect is probably due to the coating of LD particles. Mechanical release of doxorubicin via HIUS may be used to increase drug penetration into metastatic tissue. Further studies are required to investigate the impact and therapeutic possibilities of LD on tumor cells during PIPAC or heated intraperitoneal chemotherapy applications and to investigate the optimal conditions to use chemotherapeutic agents in the treatment of PM.

\section{Acknowledgements}

Not applicable.

\section{Funding}

The present study was funded by institutional funds of the Faculty of Veterinary Medicine, Wroclaw University of Environmental and Life Sciences.

\section{Availability of data and materials}

The datasets used and/or analyzed during the present study are available from the corresponding author on reasonable request.

\section{Authors' contributions}

AM designed the present study, performed experiments and analyzed the data. MA assisted in cryosectioning and performed data analysis and interpretation. VK helped in writing the manuscript, performed PIPAC procedures, and was involved in designing the study and data interpretation. VK supervised the study, drafted and critically revised the manuscript for important intellectual content. JK performed experiments and constructed the schematic diagram. KK and PM performed experiments. MA drafted and critically revised the manuscript for important intellectual content. TK designed the study, performed experiments and drafted the manuscript.

\section{Ethics approval and consent to participate}

The experiments were performed in an ex vivo model using commercially available tissue samples. Therefore, no approval from the Institutional Review Board and the Local Board on Animal Care were required.

\section{Patient consent for publication}

Not applicable.

\section{Competing interests}

The authors declare that they have no competing interests.

\section{References}

1. Solass W, Kerb R, Mürdter T, Giger-Pabst U, Strumberg D, Tempfer C,Zieren J,Schwab M and Reymond MA: Intraperitoneal chemotherapy of peritoneal carcinomatosis using pressurized aerosol as an alternative to liquid solution: First evidence for efficacy. Ann Surg Oncol 21: 553-559, 2014.

2. Göhler D, Khosrawipour V, Khosrawipour T, Diaz-Carballo D Falkenstein TA, Zieren J, Stintz M and Giger-Pabst U: Technical description of the microinjection pump (MIP $\left.{ }^{\circledR}\right)$ and granulometric characterization of the aerosol applied for pressurized intraperitoneal aerosol chemotherapy (PIPAC). Surg Endosc 31: 1778-1784, 2017

3. Khosrawipour V, Khosrawipour T, Kern AJ, Osma A, Kabakci B, Diaz-Carballo D, Förster E, Zieren J and Fakhrian K: Distribution pattern and penetration depth of doxorubicin after pressurized intraperitoneal aerosol chemotherapy (PIPAC) in a postmortem swine model. J Cancer Res Clin Oncol 142: 2275-2280, 2016. 
4. Khosrawipour V, Khosrawipour T, Falkenstein TA Diaz-Carballo D, Förster E, Osma A, Adamietz IA, Zieren J and Fakhrian K: Evaluating the effect of micropump $\subset$ position, internal pressure and doxorubicin dosage on efficacy of pressurized intra-peritoneal aerosol chemotherapy (PIPAC) in an ex vivo model. Anticancer Res 36: 4595-4600, 2016.

5. Khosrawipour V, Khosrawipour T, Diaz-Carballo D, Förster E, Zieren J and Giger-Pabst U: Exploring the spatial drug distribution pattern during pressurized intraperitoneal aerosol chemotherapy (PIPAC). Ann Surg Oncol 23: 1220-1224, 2016.

6. Khosrawipour T, Schubert J, Khosrawipour V, Chaudhry H, Grzesiak J, Arafkas M and Mikolajczyk A: Particle stability and structure on the peritoneal surface in pressurized intra-peritoneal aerosol chemotherapy (PIPAC) analysed by electron microscopy: First evidence of a new physical concept for PIPAC. Oncol Lett 17: 4921-4927, 2019.

7. Mikolajczyk A, Khosrawipour V, Schubert J, Grzesiak J, Chaudhry H, Pigazzi A and Khosrawipour T: Effect of liposomal doxorubicin pressurized intra-peritoneal aerosol chemotherapy (PIPAC). J Cancer 9: 4301-4305, 2018.

8. Khosrawipour V, Khosrawipour T, Hedayat-Pour Y, Diaz-Carballo D, Bellendorf A, Böse-Riberio H, Mücke R, Mohanaraja N, Adamitz IA and Fakhrian K: Effect of whole abdominal irradiation on penetration depth of doxorubicin in normal tissue after pressurized intraperitoneal aerosol chemotherapy (PIPAC) in a post-mortem swine model. Anticancer Res 37: 1677-1680, 2017.

9. Khosrawipour V,Bellendorf A, Khosrawipour C, Hedayat-Pour Y, Diaz-Carballo D, Förster E, Mücke R, Kabakci B, Adamietz IA and Fakhrian K: Irradiation does not increase the penetration depth of doxorubicin in normal tissue after pressurized intra-peritoneal aerosol chemotherapy (PIPAC) in an ex vivo model. In Vivo 30: 593-597, 2016.

10. Khosrawipour V, Giger-Pabst U, Khosrawipour T, Pour YH, Diaz-Carballo D, Förster E, Böse-Ribeiro H, Adamietz IA, Zieren J and Fakhrian K: Effect of irradiation on tissue penetration depth of doxorubicin after pressurized intra-peritoneal aerosol chemotherapy (PIPAC) in a novel ex-vivo model. J Cancer 7: 910-914, 2016.

11. Harrison LE, Bryan M, Pliner L and Saunders T: Phase I trial of pegylated liposomal doxorubicin with hyperthermic intraperitoneal chemotherapy in patients undergoing cytoreduction for advanced intra-abdominal malignancy. Ann Surg Oncol 15: $1407-1413,2008$

12. Salvatorelli E, De Tursi M, Menna P, Carella C, Massari R, Colasante A, Iacobelli S and Minotti G: Pharmacokinetics of pegylated liposomal doxorubicin administered by intraoperative hyperthermic intraperitoneal chemotherapy to patients with advanced ovarian cancer and peritoneal carcinomatosis. Drug Metab Dispos 40: 2365-2373, 2012.

13. Hirano $K$ and Hunt CA: Lymphatic transport of liposome-encapsuled agents: Effect of liposome size following intraperitoneal administration. J Pharm Sci 74: 915-921, 1985.

14. Carron PL, Padilla M and Maurizi Balzan J: Nephrotic syndrome and acute renal failure during pegylated liposomal doxorubicin treatment. Hemodial Int 18: 846-847, 2014.

15. Ansari L, Shiezadeh F, Taherzadeh Z, Nikoofal-Sahlabadi S Momtazi-Borojeni AA, Sahebkar A and Eslami S: The most prevalent side effects of pegylated liposomal doxorubicin monotherapy in women with metastatic breast cancer: A systemic review of clinical trials. Cancer Gene Ther 24 : 189-193, 2017.

16. Rizzitelli S, Guistetto P, Faletto D, Delli Castelli D, Aime S and Terreno E: The release of Doxorubicin from liposomes monitores by MRI and triggered by a combination of US stimuli led to a complete tumor regression in a breast cancer mouse model. J Control Release 230: 57-63, 2016.

17. Lyon PC, Griffiths LF, Lee J, Chung D, Carlise R, Wu F, Middelton MR, Gleeson FV and Coussios CC: Clinical trial protocol for Tardox: A phase I study to investigate the feasibility of target release of lyso-thermosensitive liposomal doxorubicin (ThermoDox ${ }^{\circledR}$ ) using focused ultrasound in patients with liver tumors. J Ther Ultrasound 5: 28, 2017.

18. Khosrawipour V,Diaz-Carballo D, Acikelli AH, KhosrawipourT, Falkenstein TA, Wu D, Zieren J and Giger-Pabst U: Erratum to: Cytotoxic effect of different treatment parameters in pressurized intraperitoneal aerosol chemotherapy (PIPAC) on the in vitro proliferation of human colonic cancer cells. World J Surg Oncol 15: 94, 2017
19. Khosrawipour V, Mikolajczyk A, Schubert J and Khosrawipour T: Pressurized intra-peritoneal aerosol chemotherapy (PIPAC) via endoscopical microcatheter system. Anticancer Res 38: 3447-3452, 2018

20. Flessner MF, Choi J, Credit K, Deverkadra R and Henderson K: Resistance of tumor intestinal pressure to the penetration of intraperitoneally delivered antibodies into metastatic ovarian tumors. Clin Cancer Res 11: 3117-3125, 2005.

21. Holzer AK, Katano K, Klomp LW and Howell SB: Cisplatin rapidly down-regulates its own influx transporter hCTR1 in cultured human ovarian carcinoma cells. Clin Cancer Res 10: 6744-6749, 2004

22. Mikolajczyk A, Khosrawipour V, Schubert J, Plociennik M, Nowak K, Fahr C, Chaudhry H and Khosrawipour T: Feasibility and characteristics of pressurized aerosol chemotherapy (PAC) in the bladder as a therapeutical option in early-stage urinary bladder cancer. In Vivo 32: 1369-1372, 2018.

23. Schubert J, Khosrawipour V, Chaudhry H, Arafkas M, Knoefel WT, Pigazzi A and Khosrawipour T: Comparing the cytotoxicity of taurolidine, mitomycin $\mathrm{C}$, and oxaliplatin on the proliferation of in vitro colon carcinoma cells following pressurized intra-peritoneal aerosol chemotherapy (PIPAC). World J Surg Oncol 17: 93, 2019.

24. Mikolajczyk A, Khosrawipour V, Schubert J, Chaudhry H, Pigazzi A and Khosrawipour T: Particle stability during pressurized intra-peritoneal aerosol chemotherapy (PIPAC). Anticancer Res 38: 4645-4649, 2018.

25. Sharma P, Mehta M, Dhanjal DS, Kaur S, Gupta G, Singh H, Thangavelu L, Rajeshkumar S, Tambuwala M, Bakshi HA, et al: Emerging trends in the novel drug delivery approaches for the treatment of lung cancer. Chem Biol Interact 309: 108720, 2019.

26. Kai M,Ziemys A, Liu YT, Kojic M, Ferrari M and Yokoi K: Tumor site-dependent transport properties determine nanotherapeutics delivery and its efficacy. Transl Oncol 12: 1196-1205, 2019.

27. Lokerse WJM, Bolkestein M, Dalm SU, Eggermont AMM, de Jong M, Grüll $\mathrm{H}$ and Koning GA: Comparing the therapeutic potential of thermosensitive liposomes and hyperthermia in two distinct subtypes of breast cancer. J Control Release 258: 34-42, 2017.

28. Falkenstein TA, Götze TO, Ouaissi M, Tempfer CB, Giger-Pabst U and Demtröder C: First clinical data of pressurized intraperitoneal aerosol chemotherapy (PIPAC) as salvage therapy for peritoneal metastatic biliary tract cancer. Anticancer Res 38: 373-378, 2018.

29. Khosrawipour T, Khosrawipour V and Giger-Pabst U: Pressurized intra peritoneal aerosol chemotherapy in patients suffering from peritoneal carcinomatosis of pancreatic adenocarcinoma. PLoS One 12: e0186709, 2017.

30. Armstrong DK, Fleming GF, Markman M and Bailey HH: A phase I trial of intraperitoneal sustained-release paclitaxel microspheres (Paclimer) in recurrent ovarian cancer: A Gynecologic Oncology Group study. Gynecol Oncol 103: 391-396, 2006.

31. Sugiyama T, Kumagai S, Nishida T, Ushijima K, Matuso T, Yakushiji M, Hyon SH and Ikada Y: Experimental and clinical evaluation of cisplatin-containing microspheres as intraperitoneal chemotherapy for ovarial cancer. Anticancer Res 18: 2837-2842, 1998

32. Lyon PC, Gray MD, Mannaris C, Folkes LK, Stratford M, Campo L, Chung DYF, Scott S, Anderson M, Goldin R, et al: Safety and feasibility of ultrasound-triggered targeted drug delivery of doxorubicin from thermosensitive liposomes in liver tumours (TARDOX): A single-centre, open-label, phase 1 trial. Lancet Oncol 19: 1027-1039, 2018.

33. Besse HC, Bos C, Zandvliet MMJM, van der Wulff-Jacobs K, Moonen CTW and Deckers R: Triggered radiosensitizer delivery using thermosensitive liposomes and hyperthermia improves efficacy of radiotherapy: An in vitro proof of concept study. PLoS One 13: e0204063, 2018.

This work is licensed under a Creative Commons Attribution-NonCommercial-NoDerivatives 4.0 International (CC BY-NC-ND 4.0) License. 